\title{
MITO E MEMÓRIA NA CONSTRUÇÃO DE UMA IDENTIDADE LOCAL
}

\author{
Julie Antoinette Cavignac
}

RESUMO: A partir des résultats de recherches menées au Rio Grande do Norte portant sur la mémoire et la tradition orale, nous traitons des aspects ethographiques de la création narrative à propos de l'émergence d'une nouvelle histoire locale. Nous choisissons d'utiliser une perspective théorique et methodologique pluridisciplinaire inspirée par le structuralisme qui, d'un côté, traite des récits, des identités et des representations symboliques et, d'un autre, se propose d'analyser les aspects liés à l'historiographie, à la mémoire sociale et à la construction d'une réflexion autour du sens de l'histoire locale. Les images relatives à un passé commun apparaissent régulièrement et d'une façon homogène et se trouvent inscrites dans des récits appartenant à un corpus important qui est rapidemment classé comme folklore. L'analyse comparée entre des textes oraux et des registres narratifs plus discrets, révèle des catégories natives qui organisent le monde social et naturel et permettent de comprendre comment les acteurs réélaborent leur histoire et leur identité.

PALAVRAS-CHAVE: memória, oralidade, cosmologia.

São ilhas afortunadas São terras sem ter logar, Onde o Rei mora esperando. Mas, se vamos dispertando, Cala a voz, e há só o mar.

Fernando Pessoa ${ }^{1}$

O surgimento de um discurso antropológico moderno, que integra a perspectiva histórica, é tido como a última revolução significativa das Ciências Humanas. Nesse sentido, além de enfraquecer as especificidades tradicionalmente atribuídas às duas disciplinas, as aproximações entre a história e a antropologia mudam o estatuto dos textos coletados pelos etnógrafos: de experiência vivida tornam-se documentos enigmáticos ou instrumentos para reivindicações de direitos ancestrais. Definidas tradicionalmente como mitos, sendo textos fundadores fixados pela tradição oral, as narrativas aparecem hoje multiformes, reveladoras de fatos históricos não registrados ou de lógicas culturais mais perenes (BIDOU, 1991). É como se os "selvagens" tivessem desaparecido com seus mitos. Essa concepção simplista leva antropólogos mais medrosos a não se arriscar no campo escorregadio da análise estrutural fora das áreas indígenas. Além disso, como todo objeto de investigação atual, as análises produzidas terminam por escapar do domínio do etnógrafo, sendo, às vezes, reapropriadas por seus locutores como marcadores de uma autenticidade reencontrada. Estes se apressam em mostrar "o livro" para os incrédulos.

Professora Adjunta do Programa de Pós-Graduação em Antropologia Social, Departamento de Antropologia da UFRN. Uma versão preliminar do artigo foi publicada na revista virtual Comunicologia, da Universidade Católica de Brasília, disponível no site $<$ http://www.ucb.br/comsocial/comunicologia/>.

${ }^{1}$ As Ilhas afortunadas - "O encoberto", Mensagem, III parte. 
Embora o método estruturalista tenha conhecido duras críticas ao longo dos últimos decênios sobretudo por parte dos historiadores -, ele ainda aparece como sendo o instrumento mais adequado para encontrar a significação escondida nas profundezas das palavras transmitidas de geração em geração e organizadas em narrativas. Porém, detalhes importantes ligados ao caráter localizado e histórico dos mitos são, tradicionalmente, deixados de lado; as histórias, por sua vez, trazem mais do que formas universais de pensamento humano, elementos de uma filosofia autóctone (VIVEIROS DE CASTRO, 2002). Assim, pensamos encontrar nas lendas e nos contos maravilhosos das sociedades que escolhem a oralidade como forma de comunicação, uma versão local da história, uma memória dos vencidos (WACHTEL, 1990). Esses conjuntos de enunciados narrativos não são documentos - na acepção dos historiadores -, pois não oferecem um reflexo fiel dos acontecimentos, mas conservam vivas as feridas dos seus ancestrais (PRICE, 1990) $^{2}$. É o caso dos textos orais que versam sobre o passado das populações que foram pouco estudadas pela antropologia brasileira, como é o caso dos grupos camponeses nordestinos, sobretudo do interior. O material coletado em campo é composto de lembranças pessoais, de genealogias, de contos, de versos ou mesmo de silêncios inexplicáveis muito mais do que mitos, tais como estes são geralmente definidos. O ecletismo dos temas abordados e a facilidade com a qual o locutor passa de uma história para outra revelam a existência de uma permeabilidade entre os registros narrativos e uma variabilidade do discurso. Apesar disso, o registro narrativo não representa uma fonte de conflito, pelo contrário. As línguas se soltam, as portas se abrem, as cadeiras vão para as calçadas na hora de uma boa conversa! Assim, atrás desta primeira impressão de fugacidade e de leveza, esconde-se uma percepção diferenciada do passado, na qual o trauma ainda é perceptível, delineando-se uma visão singular do mundo.

A análise comparada entre textos - que, geralmente, adotam uma forma narrativa ou enunciados orais não formalizados que abrigam "pedaços de mitos" - permite-nos visualizar como os atores reelaboram a sua história e sua identidade ${ }^{3}$. Do mesmo modo, veremos como é possível chegar a uma representação bastante uniforme e original do passado, bem como encontrar categorias nativas que ordenam o mundo social e natural. Pensamos, assim, que uma reflexão sobre o estatuto do texto oral não pode fazer a economia de uma análise da encenação do passado e da definição de uma identidade nativa cujos elementos, mesmo quando transformados ou invertidos, aparecem de maneira recorrente nas versões locais da história. Propomos, aqui, trazer alguns elementos que possibilitam uma leitura dos textos míticos inscritos em épocas e temporalidades diferentes, sem abandonar completamente a perspectiva de uma antropologia inspirada pela teoria estruturalista.

\section{Túneis, holandeses e baleias}

A existência de uma história autóctone, reelaborada a cada geração, levanta problemas relacionados aos aspectos teórico-metodológicos da análise das formas narrativas em antropologia. A memória colonial e as representações simbólicas ligadas aos principais personagens da história local afloram na ocasião da evocação dos acidentes geográficos ou dos monumentos construídos, marcas do passado inscritas na paisagem. Podemos traçar um mapa dos reinos encantados e dos lugares onde são presenciados "fenômenos misteriosos" e aparições sobrenaturais. A leitura comparada dos textos da tradição oral e dos resultados da pesquisa etnográfica nos ajuda na elaboração de uma geografia e de uma história imaginárias do Rio Grande do Norte ${ }^{4}$.

As lendas de fundação das cidades juntam-se às "estórias de trancoso" ou aos contos de encantamento, bem como a algumas referências mais breves, presentes nas conversas ou em outros tipos de discursos: - Viu aquele serrote? É um reino encantado! E nada mais. Devemos nos contentar com este registro. Porém, a simples referência remete a um conjunto mais amplo, no qual verificamos um superpovoamento de entidades sobrenaturais no espaço não habitado.

\footnotetext{
${ }^{2}$ Encontramos, porém, de maneira surpreendente, a marca memorial de eventos históricos nas narrativas coletadas. Assim, a lenda de fundação da cidade de Nísia Floresta, antiga aldeia indígena, lembra o deslocamento da santa (Nossa Senhora do Ó) para a cidade vizinha, São José do Mipibu, antiga missão capuchinha; fato que aconteceu efetivamente em 1740. Para mais detalhes, ver CAVIGNAC (2005).

${ }^{3}$ Este artigo apresenta uma reflexão sobre a questão narrativa em pesquisas realizadas em vários locais do Rio Grande do Norte: entre 1990-1994, no Seridó e no Oeste, nas cidades de Carnaúba dos Dantas e Campo Grande; entre 1995 e 1999 na Zona Norte de Natal; e, desde 2000, em cidades do litoral sul do estado. Comunicação inicialmente apresentada em 2001, no Congresso da ABANNE (Recife, PE.), com o título: "O tempo dos holandeses: imagens discursivas, paisagem e monumentos de um passado esquecido".

${ }^{4}$ Ensaiamos um mapa dos encantamentos encontrados no litoral do Rio Grande do Norte, onde se concentrou a ocupação colonial, mas poderíamos ampliar o mapa a outras regiões. Ver o mapa no Anexo 1 deste volume.
} 
No "mato", vivem, ainda, os espíritos que protegem as caças, maltratam os cachorros, assobiam nos ouvidos dos caçadores, trançam os cabelos dos cavalos, jogam pedras, etc. São eles: Comadre Fulozinha, Caipora e Saci, que entram numa dança infernal com as Mães d'Água, as antas esfoladas, as onças que dão saltos extraordinários, os carneiros de ouro voadores, as almas dos mortos sem sepultura, os santos padroeiros encontrados nas lagoas, etc. Essa profusão de entidades sobrenaturais lembra constantemente aos homens os perigos das zonas desertas, das matas e das serras.

$\mathrm{Na}$ origem das cidades, os santos foram geralmente achados num meio inóspito: em pleno sertão, perdidos "no meio do mundo", perto de uma pedra, no tronco de um juazeiro, no munfumbal ou protegidos das águas de um rio caudaloso por um pé de Aninga, afogados no mar, no rio ou numa lagoa turva. Quando são levados para longe do seu lugar de vida - os santos têm vida, pois são poderosos! retornam, obstinadamente, até o local de origem, para seus devotos construírem uma capela. Os animais fabulosos e as almas coexistem nas grutas, nos rochedos, nas "casas de pedras", que são as ruínas abandonadas pelos holandeses ou as igrejas das antigas missões capuchinhas, tomadas pela vegetação nativa e destruídas pelos caçadores de tesouros. São serpentes, baleias, princesas ou curiosos que foram capturados e que se "encantaram". Não voltaram mais. Pertencem, a partir de então, a um mundo adormecido. Escutam-se os gemidos, as súplicas e as tristes melopéias dos condenados à errância eterna. Nas serras, nos reinados encantados, vêem-se princesas e sereias, ouvem-se bandas tocando música e barulhos de locomotiva que dão calafrios aos passantes solitários.

Os encantamentos respondem a uma mesma lógica, a de uma ocupação sobrenatural do espaço inabitado, relacionando-as a um tempo passado não definido, porém, anterior à chegada dos antepassados dos atuais moradores. Não é raro escutar: - Naquele tempo, era só mato. Designando um momento anterior à colonização, nossos interlocutores nos levam de volta para o registro do mito, de novo esfacelado: - No tempo que os bichos falavam.

Começa aqui uma longa "estória de trancoso" que, geralmente, termina por falta de ouvintes. História mítica por excelência, é uma fábula em que os animais dominam a cena, chamando-se de "camarada macaco" ou de "comadre onça". Nesse conjunto narrativo, verificamos a repetição e a insistência sobre um detalhe pertencente a determinado acontecimento histórico que geralmente difere da versão dos historiadores. Assim, encontramos índios vindos da Europa e holandeses se metamorfoseando em "negrinhos" com a luz do sol. Para entendermos essas inversões e metamorfoses, é preciso notar que, tanto na historiografia como na memória oral, há evidências múltiplas de uma aliança entre batavos e índios tapuias, terríveis guerreiros do atual sertão do Rio Grande do Norte ${ }^{5}$.

\section{Índios da Itália, holandeses do Brasil}

A presença do elemento narrativo anuncia a entrada do sobrenatural na elaboração e na reivindicação de uma identidade, pelo viés da reconstrução da história oficial e da rememoração. Partindo dessa idéia, podemos lembrar os exemplos de narrativas citados ou referências a estes temas - tanto na literatura oral, como nas obras deixadas por historiadores ou folcloristas - que apresentam monstros subterrâneos (serpentes, baleias) ou espíritos morando nas entranhas das montanhas. Também é comum os holandeses tomarem o papel dos portugueses na colonização do espaço; foram eles que descobriram, exploraram e levaram as riquezas para fora do Brasil. No imaginário local, tudo foi construído por eles: pontes, pinturas rupestres e até igrejas! (CARVALHO, apud MELLO, 1979; CAVIGNAC, 2005). Podemos citar, também, várias testemunhas afirmando a "importação" dos índios da Europa ou negando as raízes africanas e escravas. A discrição que as pessoas mantém sobre uma origem étnica diferenciada é acrescentada por uma impossibilidade de contar a história dos seus antepassados. Assim, quando temos a sorte de encontrar um descendente de "índio" ou de "caboclo" assumido, gravamos sempre a mesma frase: - Minha avó foi caçada a dente de cachorro e casco de cavalo.

Em todos os casos, a história aparece como censurada, proibida, pois não consegue passar dessa lembrança brutal. E não se tratam de fatos isolados: em todo o Nordeste encontramos o mesmo registro memorial. Parece que as reinterpretações das origens étnicas diferenciadas integram-se em uma única narrativa, na qual se encontram todos os elementos do mito. De novo, em pedaços.

\footnotetext{
${ }^{5}$ Ver o artigo "Um mundo encantado: memória e oralidade no sertão do Seridó". In: RENK, Arlene; GONÇALVES, Carlos Walter Porto; GODOI, Emília Pietrafesa de et alli. A diversidade de formas do campesinato brasileiro. História social do campesinato. Tomo IV, 2006.
} 
Assim, é marcante a insistência com que as pessoas designam os batavos, europeus que ficaram menos tempo no domínio da Capitania - vinte anos durante o século XVII! Eles são apresentados como os construtores da maior parte dos monumentos históricos, inclusive os mais recentes. Aqui e ali, de forma ímpar, os holandeses aparecem como aqueles que deixaram os marcos históricos no interior do Rio Grande do Norte - pinturas indígenas, em particular - e uma "descendência": após a vitória dos portugueses, eles teriam se refugiado no sertão, sobretudo no Seridó. A prova disso é a grande quantidade de "galegos" na região, de pele clara e de olhos azuis. Em Natal, eles ergueram o Forte do Reis Magos, a ponte de ferro do rio Potengi - construída por ingleses no início do século XX! - , na Zona Norte, duas casas de pedra, que serviam para armazenar as suas munições e, no local da antiga missão jesuíta dos Paiacu, no rio Sibaúma, em Tibau do Sul, há pedras misteriosas que abrigaram o "curtume dos padres velhos". Por outro lado, a referência a minas e túneis, sobretudo aquele ligando Extremoz - antiga missão jesuíta e aldeia indígena - ao Forte dos Reis Magos, passando então pela Zona Norte, atesta a existência de construções subterrâneas de dimensões extraordinárias. Construíram também a igreja e o cruzeiro de Vila Flor - ainda antiga missão carmelita -, bem como a antiga cadeia pública da cidade, que hoje abriga a Câmara de Vereadores. Nesse edifício, é dito também que se encontra um túnel que "vai dar" nos Sete Buracos $^{6}$ e na Barra de Cunhaú - onde uma baleia impediria a passagem -, "subterrâneo" feito pelos holandeses para esconder as riquezas pilhadas da região. Devido à cor branca da pele e à fragilidade de seus olhos azuis, os batavos preferiam trabalhar protegidos do sol e à noite, às escondidas, tendo, dessa forma, maior facilidade para embarcar os tesouros da colônia em seus navios, que partiam para a Europa levando o ouro e os diamantes!

Nessa perspectiva, a figura do holandês aparece ligada ao mistério, à riqueza e, em muitos casos, a um infra-mundo. Ela vem se "encaixar" num sistema simbólico já organizado, propondo uma interpretação nativa do evento histórico importante que é a colonização (SAHLINS, 1987). Portanto, a ação holandesa no imaginário local está associada à construção dos túneis e à exploração de ouro e riquezas naturais. Figura extrema da alteridade, o holandês é caracterizado como um pilhador e, em contrapartida, um hábil engenheiro, realizando grandes obras que denunciam a sua sabedoria e seu empenho $^{7}$. A presença de tesouros escondidos nas paredes ou no subsolo dos monumentos nos remete diretamente às estórias de botija e às aparições noturnas, bem como à existência de lugares misteriosos contendo tesouros, mundos adormecidos e subterrâneos, povoados por seres misteriosos, ancestrais esquecidos, animais monstruosos e espíritos diversos. Retornamos ao encantamento. Mais do que o simples adormecimento encontrado nos contos de fada, o encantamento se refere a um poder sobrenatural suscetível de ser reativado a qualquer momento. A vitalidade das forças espirituais se confunde com as dos santos padroeiros que são "achados no mato". Portanto, tornam-se visíveis e respondem à mesma lógica; a de uma presença de forças ctônicas ou aquáticas antigas - pertencendo a um outro mundo - que podem se manifestar na natureza, nas pedras e nas rochas, metamorfosear-se em animais - sobretudo pássaros -, ou revestir-se de uma aparência humana. O espaço e o tempo, desse modo, confundem-se durante o mito.

Poderíamos, também, encontrar uma configuração semelhante em outras regiões do país. No Maranhão e no Pará, os reinos encantados parecem ter ainda mais vida, eles se materializam e correspondem a um complexo ritual bastante diversificado (MAUÉS, 1990; SILVEIRA, 2003). Mais perto do Rio Grande, num contexto nordestino, os cultos afro-brasileiros (Catimbó) e indígenas (Toré, Jurema) apresentam uma devoção aos "encantados", espíritos indígenas apreciadores de vinhos de Jurema, cuja força reside, justamente, no seu poder em se esconder dos humanos. Os "espíritos do mato" saem das florestas, dos rios e das montanhas para socorrer os humanos em caso de doença ou de magia negra (BASTIDE, 1959; BANDEIRA, 1972; PRANDI, 2001). Na versão narrativa geralmente encontrada no Rio Grande do Norte na qual é apresentada uma versão edulcorada em relação a outras regiões vizinhas ou comparando com contextos religiosos específicos, o encantamento é apenas ligado a uma presença inusitada de um personagem pertencente a um passado indefinido, prisioneiro das pedras e das águas subterrâneas. O seu desencantamento é tornado possível se a pessoa que o libertar não revelar o segredo. São as histórias de botija, nas quais o felizardo proprietário do tesouro deve fugir para sempre, sem olhar para trás. Metáfora do esquecimento - atrás tem o demônio! -, o ato justifica e perpetua a tradição, deixando a possibilidade, para outros corajosos aventureiros, se arriscarem. Em suma,

\footnotetext{
${ }^{6}$ Alguns historiadores pensam que são antigas minas de ferro exploradas pelos holandeses, no município de Canguaretama, RN (MEDEIROS FILHO, 1989, 1998). Nos arredores, no Catu dos Leotério ou Catu de Cima, moram famílias reinvidicando uma identidade indígena. Em maio de 2005, houve uma audiência pública em Natal durante a qual três grupos se autodeclararam como indígenas: os "Leotério" do Catu (município de Canguaretama), os "Mendonça" do Amarelão (município de João Câmara), e os "Caboclos" de Açu.

${ }^{7}$ Para uma discussão sobre a interpretação nativa da colonização num outro contexto etnográfico, ver WACHTEL (1996).
} 
encontramos um mundo natural superpovoado por entidades sobrenaturais, correspondendo às descrições contidas nos contos de encantamento. Então, esses reinos mágicos podem ser considerados como mundos subterrâneos, adormecidos, povoados por seres fantásticos, tendo seus poderes limitados pelo sono. Esses mundos fechados são invisíveis ao olho humano sem experiência; são testemunhas de uma época desaparecida ou que se encontra num estado primordial, o da natureza selvagem. Os reinados encantados - termo genérico que, no sertão, engloba todos os lugares naturais ou que foram abandonados pelos humanos e que são agora habitados por seres sobrenaturais (montanhas, lagoas, aos quais podemos acrescentar as encruzilhadas, as casas abandonadas e mal-assombradas, etc.) - compartilham o mesmo espaço que as outras manifestações divinas ou malignas (santos, diabos, monstros, etc.), os espíritos dos mortos que vagam na face da terra ou, ainda, espíritos protetores da natureza (Caipora, Comadre Fulozinha, Mãe D’Água).

No final da análise, os reinados encantados aparecem como lugares intermediários entre o mundo dos ancestrais, o mundo selvagem e o mundo dos homens, o passado e o presente. Aproximandose de uma cosmologia definida como animista, a configuração que se desenha pressupõe uma intensa troca entre os animais, os homens e os mortos, não ficando longe das visões de mundo reveladas pelos estudos sobre as terras baixas amazônicas. Atualizados, os relatos colocam em movimento imagens de um tempo primeiro e são revitalizados pela performance e a criatividade dos locutores que dão novos conteúdos às velhas narrativas que teriam desaparecido no limbo do esquecimento. Existiria, então, um perspectivismo nordestino (VIVEIROS DE CASTRO, 2002)?

A partir dos resultados de pesquisas realizadas anteriormente, sobretudo das reflexões ligadas à investigação da memória dos moradores do sertão e de um levantamento preliminar da tradição oral de algumas antigas aldeias missionárias situadas no litoral do Rio Grande do Norte (Extremoz, Arês, Vila Flor), exemplificamos os aspectos etnográficos da criação narrativa, no que diz respeito à criação de uma "nova história local". Isto, através da leitura de textos formalizados em narrativas, bem como na avaliação de registros ligados ao tema, espalhados nos discursos das pessoas entrevistadas. Assim, em um primeiro momento, podemos analisar como os "clássicos" da literatura popular - oral e escrita - vão adaptando-se a uma nova realidade para se constituir em tradição: novos personagens e novas situações encontram-se revestidos com as velhas estruturas narrativas.

Assim foi se constituindo a certeza de que as imagens relativas a um passado comum aparecem com regularidade e homogeneidade em toda a região - afirmação válida talvez até mesmo para o Nordeste inteiro 9 . Essas imagens encontram-se inscritas, sobretudo, mas não somente, nas narrativas pertencentes a um corpus importante e pouco investigado pelos antropólogos, o que Vladimir Propp (1965, 1983) chama de "contos maravilhosos". Desde o século passado, no Nordeste, eles foram coletados, inicialmente, pelos folcloristas, e publicados junto a outras formas literárias - canções, cantigas, romances, poesias, etc. (SANTOS, 1997). Algumas lendas de fundação foram anotadas por historiadores amadores, cuja proposta era resgatar a cultura e a história local. A reiteração de um elemento narrativo ou o "deslocamento" sistemático de um monumento para uma outra época - ver as "obras" deixadas pelos holandeses - ou, ainda, a presença de monstros subterrâneos (aquáticos ou terrestres) povoando o subsolo das igrejas, das montanhas e das lagoas, mostra que estamos diante de uma configuração já sedimentada, na qual o passado é integrado ao espaço e se conjuga com representações sobrenaturais (HALBWACHS, 1990).

São temas recorrentes e dinâmicos que formam os elementos díspares de uma visão bastante instigante da história local. Nesses encaixamentos sucessivos, torna-se difícil encontrar uma origem distinta para cada um dos elementos em jogo. O rearranjo original dos elementos possibilita a mise en marche de uma lógica autóctone que já estava presente na chegada dos europeus (WACHTEL, 1990). Podemos pensar, com E. Viveiros de Castro (2002, p. 209) que:

Uma cultura não é um "sistema de crenças", mas antes - já que deve ser algo - um conjunto de estruturações potenciais da experiência, capaz de suportar conteúdos tradicionais variados e de absorver novos: ela é um dispositivo culturante ou constituinte de processamento de crenças. [aspas do original]

Dessa forma, no caso das narrativas, encontramos uma síntese original de elementos diversos que, tratados em conjunto, deixam aparecer uma lógica cultural que se mantém viva, apesar das mudanças sofridas na paisagem social e cultural da região.

\footnotetext{
${ }^{8}$ Ver CAVIGNAC (2006).

${ }^{9}$ Por exemplo, encontramos a mesma representação dos holandeses associada a um mistério no Rio Grande do Norte, na Paraíba e no Pernambuco.
} 


\section{Etno-história e o trabalho da memória}

Concebido como suporte da memória do grupo ou das suas produções simbólicas, o texto oral ganha novos adeptos com o revival dos anos setenta e a crise de objeto da antropologia. Com isso, ao mesmo tempo em que são redescobertas as tradições das populações camponesas européias, que eram até então estudadas pelos folcloristas, novos estudos aparecem para as nações jovens, tendo como enfoque principal as modificações ocorridas durante o processo colonial. Assim, as sociedades exóticas tornam-se os campos de investigação "naturais" dos antropólogos europeus e americanos, principalmente a partir da generalização dos movimentos de libertação das antigas colônias e com o surgimento de uma antropologia nativa, e, às vezes, nativista. Com esse retorno dos antropólogos ocidentais ao velho terreno dos folcloristas, a disciplina teve de elaborar novos instrumentos de investigação para estudar a tradição oral. Uma da vias mais ricas - que, às vezes, integra o estudo do texto literário - resulta da aproximação da antropologia e da história (LE GOFF, 1996; MATTOSO, 1999). Podemos perceber esse movimento, sobretudo, com o surgimento dos trabalhos da história oral e dos estudos com o objetivo explícito de resgatar a memória dos excluídos: histórias de vida adaptadas pelos pesquisadores, que eram apresentadas como textos autobiográficos ${ }^{10}$. Só hoje, com a crítica da pretensão universalista do estruturalismo e com a abertura da disciplina a outras vias de explicação, torna-se possível adotar uma perspectiva voltada para a sociedade produtora da sua história: a antropologia eliminou as visões românticas associadas às sociedades primitivas e os estudiosos constataram a presença da história e da antropologia num mesmo campo de pesquisa - o da memória.

É possível então reconstruir uma lógica de apreensão do mundo através da análise das produções narrativas. Aqui, a natureza não habitada torna-se o "lugar de vida" do sagrado autóctone e o revelador de um passado longínquo. O subsolo contém também os seres ligados ao fim do mundo (sobretudo, serpentes e animais aquáticos) ou mortos suscetíveis de ressuscitar, principalmente no caso das princesas adormecidas. Assim, a descrição minuciosa desse mundo repleto de monstros, de espíritos e de santos, que surgem como os primeiros colonizadores da região, é relatada pelos nordestinos. Isto, graças aos textos míticos, às "histórias de almas" ou aos milagres, aos romances de cordel, ou, ainda, às "estórias de trancoso".

Analisando o conjunto narrativo coletado, podemos traçar os contornos de uma cosmologia local. Desenha-se, então, uma representação do mundo original, onde o espaço sagrado segue de perto os limites do mundo habitado. O espaço sobrenatural iniciar-se-ia, desse modo, na fronteira da cidade: ao atravessar o sertão ou qualquer zona deserta, os homens devem proteger-se contra as agressões dos agentes do mundo extra-humano ou, ainda, devem procurar ganhar os seus favores, realizando rezas, práticas mágicas, oferendas, ou mesmo súplicas, no caso das aparições de Nossa Senhora. Esta representação da natureza como lugar do sagrado, associada a um passado longínquo, poderia também ser o resultado de uma resistência da cosmologia nativa à colonização.

Temos, chegando no final da análise, a convicção de que essa representação de um mundo natural-sagrado apresenta, de um modo metafórico, a colonização. Podemos, então, começar a avaliar a amplitude do fenômeno. Como é demonstrado por outros países latino-americanos, na Bolívia (WACHTEL, 1990) ou no México (GRUZINSKI, 1988), o invasor conseguiu tomar posse de terras, eliminar fisicamente as populações nativas e impor, simbolicamente, contando com a ajuda da Igreja, uma legitimidade da ocupação colonial. Ao mesmo tempo, essas narrativas nos ensinam que a elaboração da autoctonia passa necessariamente por uma reinterpretação singular da história; versão plausível do passado, mostrando que os homens continuam tecendo relações complexas e múltiplas junto aos agentes sobrenaturais autóctones. Seria uma forma de resistência das culturas nativas? ${ }^{11}$

A invisibilidade foi a estratégia mais adequada para essas populações e podemos entender as formas de denegação relacionadas à origem étnica como uma das suas principais conseqüências. Antes de tudo, queremos demonstrar que é necessário reavaliar o estudo da narrativa e que este não deve ser limitado ao estudo formal. Tentamos, aqui, entender os resultados da análise textual, à luz das observações etnográficas e dos dados históricos, para desenhar os contornos de uma cosmologia local. Produzindo afirmações historicamente possíveis para o contexto nordestino, os homens, contando estórias, repetindo anacronismos e fórmulas feitas, elaboram e reelaboram eventos passados e presentes, propondo uma reinterpretação local dos fatos reais, inspirando-se na "tradição". Por meio de uma

\footnotetext{
${ }^{10}$ Ver uma discussão mais detalhada em CAVIGNAC (2006).

${ }^{11}$ De um modo geral, nossas pesquisas atuais visam a associar a investigação histórica ligada a problemas etnográficos a uma reflexão sobre a memória e as narrativas coletadas em campo, tendo como principal preocupação a coleta do discurso ligado ao passado e à origem do grupo.
} 
pesquisa etnográfica realizada junto à coleta das narrativas, é possível reconstituir o universo cultural dos moradores, a fim de compreender a dinâmica social e suas práticas. A tradição oral, incluindo as criações narrativas e poéticas, é considerada, enquanto suporte oral de um patrimônio cultural, legitimação de uma identidade, veículo das representações coletivas e de uma história própria. É também o modo de expressão de uma memória viva, sempre reatualizada em termos locais pelos atores; memória que lembra um passado, mas também um lugar de origem que tem um papel fundante na elaboração da identidade local.

Afinal, é a ocasião de propor uma leitura cruzada dos textos orais, da realidade dos locutores, dos seus discursos e da suas narrativas. Não podemos esperar encontrar o reflexo fiel do passado nas produções literárias de um grupo particular; é preciso analisar um discurso formalizado culturalmente, levando em conta a liberdade criativa do contador, e, portanto, lembrando-se que se trata de obras de ficção. O conto poderia, então, ser definido como uma categoria do discurso nativo, uma narrativa etnográfica determinada, permitindo atingir não uma realidade presente ou passada, mas a sua modelização; a oralidade sendo determinante na perpetuação deste discurso formalizado. Uma abordagem antropológica da memória permite iniciar uma reflexão sobre a importância social (identitária) e imaginária da geografia e dos monumentos históricos. Um estudo deste tipo permite também colher o discurso sobre as representações do espaço e a percepção do mundo. Afinal, uma pesquisa de campo se torna indispensável para pôr em perspectiva os textos e a cultura que os produz; estes integrados a um contexto sócio-histórico específico.

Almas, princesas, baleias, cobras, antas esfoladas e outros encantamentos fazem irrupção na narrativa, sem avisar. Não seria, para os detentores desses tesouros enterrados, a "verdadeira história"?

A delirar, Guaracy

Na lagoa mergulhou

Seguiu a voz de Jacy

E à tona não mais voltou. (Lenda da lagoa de Papary)

\section{BIBLIOGRAFIA}

BANDEIRA, Maria de Lourdes. Os Kariris de Mirandela: um grupo indígena integrado, Estudos Baianos, UFBA, n. 6, 1972.

BASTIDE, Roger. Sociologia do folclore brasileiro. São Paulo: Anhembi, 1959.

BIDOU, Patrice. Nature du mythe. In: BONTE, Pierre; IZARD, Michel (Orgs.). Dictionnaire de l'ethnologie et de l'anthropologie. Paris: Puf, 1991. p. 491-492.

CAVIGNAC, Julie. A literatura de cordel no Nordeste do Brasil. Da história escrita ao relato oral. Trad. Nelson Patriota. Natal: EdUFRN, 2006. [Coleção nordestina]

CAVIGNAC, Julie. Retóricas do olhar e tramas da narrativa. Historicidade e mitografia em Nísia Floresta (RN). In: MARTINS, José de Souza; ECKERT, Cornelia; NOVAES, Sylvia Caiuby: $O$ imaginário $e$ o poético nas ciências sociais. Bauru, EDUSC, 2005. p. 225-270.

CAVIGNAC, Julie; LINS, Cyro Holando de Almeida; MOREIRA, Stéphanie Campos Paiva; MAUX, Augusto Carlos de Oliveira. Uma Sibaúma só! Relatório antropológico da comunidade quilombola de Sibaúma (RN). Natal: Instituto Nacional de Colonização e Reforma Agrária - INCRA, Departamento de Antropologia da Universidade Federal do Rio Grande do Norte, UFRN, 2006.

FERREIRA, Jerusa Pires. Matrices imprimées de l'oral. In: MIGOZZI, Jacques (Org.). Le roman populaire en question(s). Limoges: PULLIM, 1996. p. 487-498.

FERREIRA, Marieta de Moraes (Org.). Usos e abusos da história oral. Rio de Janeiro: FGV, 1996.

FERREIRA, Marieta de Moraes. História oral. Rio de Janeiro: Diadorim, 1994.

GOODY, Jack. La raison graphique. La domestication de la pensée sauvage. Trad. Jean Bazin. Paris: Minuit, 1979.

GRUZINSKI, Serge. La colonisation de l'imaginaire. Sociétés indigènes et occidentalisation dans le Mexique espagnol XVI'-XVIIIe siècle. Paris: Gallimard, 1988.

HALBWACHS, Maurice. A memória coletiva. São Paulo: Vertice, 1990.

HOBSBAWN, Eric J.; RANGER, Terence (Org.). The invention of tradition. Cambridge: Cambridge University Press, 1983.

LANNA, Marcos. P. D. A dívida divina: troca e patronagem no nordeste brasileiro. Campinas: Unicamp, 1995. 
LE GOFF, Jacques. História e memória. 4.ed. Campinas: Unicamp, 1996.

LÉVI-STRAUSS, Claude. Anthropologie structurale. Paris: Plon (réed.), 1974.

LÉVI-STRAUSS, Claude. La structure et la forme. Réflexions sur un ouvrage de Vladimir Propp. In: Anthropologie structurale deux. 2.ed. Paris: Plon, 1996. p. 139-173.

MATTOSO, Katia de Queirós; SANTOS, Idelette Muzart Fonseca dos; ROLLAND, Denis (Eds). Matériaux pour une histoire culturelle du Brésil. Objets, voix et mémoires. Paris: L'Harmattan, coll., 1999. [Recherches Amérique latine - série Brésil]

MAUÉS, Raymundo Heraldo. A ilha encantada - Medicina e Xamanismo numa comunidade de pescadores. Belém: Universidade Federal do Pará, 1990.

MEDEIROS FILHO, Olavo. No rastro dos Flamengos. Natal: Fundação José Augusto, 1989.

MEDEIROS FILHO, Olavo. Os holandeses na Capitania do Rio Grande. Natal: Instituto Histórico e Geográfico do RN, 1998.

MELLO, Evaldo Cabral de. Imagens do Brasil holandês 1630-1654. Rio de Janeiro, São Paulo: Fundação Nacional Pró-Memória, Ministério da Cultura, Fundação Maria Luisa e Oscar Americano, 1987.

MELLO, José Antônio Gonçalves de. Influência da ocupação holandesa na vida e na cultura do norte do Brasil. 2.ed. Recife: BNB, coll. Pernambucana (1947), 1979.

MENEZES, Eduardo Diathay Bezerra de (Org.). Para uma leitura sociológica da literatura de cordel, Rev. de Ciências Sociais, v. VIII, n. 1-2, 1977.

NORA, Pierre (Org.). Les lieux de mémoire. Paris: Gallimard, 1984-1993. 7v.

NOVAES, Adauto (Org.). Tempo e história. São Paulo: Cia das Letras, Secretaria Municipal da Cultura, 1992.

PAULME, Denise. La mère dévorante. Essais sur la morphologie des contes africains. Paris: Gallimard, 1976.

PRANDI, Reginaldo (Org.). Encantaria brasileira. Rio de Janeiro: Pallas, 2001.

PRICE, Richard. First Time: the Historical Vision of an Afro-American People. John Hopkins University Press, 1983.

PRICE, Richard. Les premiers temps. Paris: Seuil, 1994.

PROPP, Vladimir J. A. Les racines historiques du conte merveilleux. 2.ed. Trad. Lise Gruel-Apert. Paris: Gallimard, 1983. [Préface de Daniel Fabre et de Jean-Claude Schmidt]

PROPP, Vladimir J. A. Morphologie du conte. Paris: Seuil (réed.), 1965.

ROMERO, Sílvio. Estudos sobre a poesia popular do Brasil. 2.ed. Petrópolis: Vozes, 1977.

ROMERO, Silvio. Folclore brasileiro. Cantos populares do Brasil. 2.ed. Rio de Janeiro: José Olympio, 1954. 2v.

SAHLINS, Marshall. Ilhas de História. Rio de Janeiro: Jorge Zahar Editor, 1997.

SANTOS, Idelette Muzart Fonseca dos. La littérature de cordel au Brésil. Mémoire des voix, grenier d'histoires. Paris: L'Harmattan, 1997. [Collection "Recherches/Amériques Latines "]

SILVEIRA, Marcio Silva da. A pajelança marajoara e a vida política no município de Sure (Pará, Brasil). Comunicação apresentada na Reunião da Antropologia do Mercosul, 2003.

SLATER, Candace. A vida no barbante. A literatura de cordel no Brasil. Trad. Octavio Alves Velho. Rio de Janeiro: Civilização Brasileira, 1984.

TEDLOCK, Dennis. On the translation of style in oral narrative, Journal of American Folklore, n. 84, p. 114-133, 1971.

TEDLOCK, Dennis. The spoken word and the work of interpretation. Philadelphia: University of Pennsylvania Press, 1983.

TEDLOCK, Dennis. The witches were saved. A Zuni origin story. Journal of American Folklore, n. 101, p. 312-320, 1988.

TERRA, Ruth Brito Lemos. Memória de lutas: literatura de folhetos no Nordeste. 1893-1930. São Paulo: Global, 1983.

WACHTEL, Nathan. Deuses e Vampiros. De volta a Chipaya. São Paulo: Edusp, 1996.

WACHTEL, Nathan. Le retour des ancêtres: les indiens Urus de Bolivie, XXe-XVIe siècle. Essai d'histoire regressive. Paris: Gallimard, 1990.

YATES, Frances A. The Art of Memory. London: Henley, Routledge and Kegan, 1966.

ZUMTHOR, Paul. Introduction à la poésie orale. Paris: Seuil, 1983. 